\title{
Development and Loss of Early Projections in a Sexually Dimorphic Rat Spinal Nucleus
}

\author{
D. R. Sengelaub and A. P. Arnold \\ Department of Psychology and Laboratory of Neuroendocrinology, Brain Research Institute, \\ University of California at Los Angeles, Los Angeles, California 90024
}

\begin{abstract}
The spinal nucleus of the bulbocavernosus (SNB) contains 3-4 times more motoneurons in adult male rats compared to females. This large dimorphism in motoneuron number is produced perinatally by an androgen-regulated cell death. To determine if the early projections of the SNB to its target musculature may be involved in the creation of this sexual dimorphism, and how these projections might interact with androgens, HRP tracing techniques were used to retrogradely label SNB motoneurons during prenatal and postnatal development in males, females, and masculinized females. HRP labeling revealed that the prenatal formation of early projections of the SNB in males and females is comparable. SNB motoneuron number increases through the day before birth in all groups, and during this increase, labeled cells can be seen outside the SNB, which we hypothesize are in the process of migrating into the SNB from the lateral motoneuron column. Postnatally, SNB motoneuron number declines, especially in females, and by postnatal day 10 the sexual dimorphism in cell number and projections has been established. These results indicate that although masculine androgen levels are critical in determining SNB motoneuron survival, they are not necessary for initial axon outgrowth of SNB motoneurons. However, androgens may be involved in the regulation of SNB motoneuron migration and the stabilization of the peripheral projections of the SNB. Both male and female SNB motoneuron axons are present at their target muscles during the time in which sex differences in motoneuron number develop, suggesting that the interaction of SNB motoneurons with their targets could be involved in the dimorphic regulation of cell survival.
\end{abstract}

During development, motoneurons form highly specific connections with their target musculature (Landmesser, 1980; Tosney and Landmesser, 1984). These connections are typically formed before muscle individualization (Lance-Jones, 1979; Romer, 1927) and before the period of normally occurring cell death commonly observed in developing neuromuscular systems (Chu-Wang and Oppenheim, 1978; Hamburger, 1975). The survival of developing motoneurons depends on the presence of their target musculature (Hamburger and Levi-Montalcini, 1949), and studying the interactions of motoncurons with their targets has clarified the processes that regulate cell death (Oppenheim, 1981). In this study, we have examined the development of the projections from a spinal motor nucleus that undergoes an androgen-regulated death of motoneurons. Detcrmining whether androgens interact with the development

Received July 19, 1985; revised Oct. 21, 1985; accepted Nov. 15, 1985.

We wish to thank S. Glaessner and E. M. Kurz for their excellent technical assistance. This work was supported by PHS Grant HD15021 and NIH Postdoctoral Fellowship NS07355-01.

Correspondence should be addressed to D. R. Sengelaub at the above address. Copyright (C) 1986 Society for Neuroscience $0270-6474 / 86 / 061613-08 \$ 02.00 / 0$ of these projections might yield some clues as to how androgens regulate motoneuron survival in this system, as well as providing insight into the regulation of cell survival in general.

The spinal nucleus of the bulbocavernosus (SNB) is a small group of motoneurons located in the fifth and sixth lumbar segments of the rat spinal cord. In males, these motoneurons innervate the perineal muscles bulbocavernosus and levator ani (Breedlove and Arnold, 1980; Schroder, 1980), as well as the anal sphincter (McKenna and Nadelhaft, 1984). In females, these muscles are present at birth, but the bulbocavernosus and levator ani atrophy early in postnatal development (Cihak et al., 1970), leaving only the anal sphincter to be innervated by the SNB motoneurons. This difference in the periphery is reflected centrally as well, in that the SNB of males contains approximately 200 motoneurons compared to only 60 in females (Breedlove and Arnold, 1980).

In a previous study (Nordeen et al., 1984, 1985), we described the development of the sex difference in SNB motoneuron number. This study revealed that the sex difference in SNB motoneuron number is not always present. Five days before birth the number of recognizable motoneurons in the SNB in Nisslstained material is only a fraction of later levels, and this number increases in both sexes through the day before birth, at which time there are substantially more motoneurons present in the SNB than there are in adult animals. SNB motoneuron number declines after this peak, and the adult sex difference is established by a differential death of motoneurons during this critical perinatal period. Motoneuron loss from the day before birth to postnatal day (P) 10 is significantly greater in females (70 vs only $25 \%$ in males), and during this period of loss significantly more degenerating cells can be observed in the area in the SNB of females than in males and masculinized females. Androgens are critical in determining SNB motoneuron number (Breedlove and Arnold, 1983a, b), and treatment with testosterone propionate (TP) significantly reduces the loss of SNB motoneurons (Breedlove, 1984; Nordeen et al., 1984, 1985), as well as the incidence of degenerating cells in females (Nordeen et al., 1984 1985). Thus, masculinized females possess male-typical SNB motoneuron numbers and also retain the perineal muscles that would normally have atrophicd.

To understand how androgens prevent SNB motoneuron death, it is important to determine the timing of SNB axon outgrowth and contact with the target muscles relative to the period during which sex differences in motoneuron number develop. For example, the greater death of SNB motoncurons in females could result from a deficit in axon outgrowth or a failure to contact the target musculature. We therefore used HRP tracing techniques to label SNB motoneurons retrogradely during the period in which the nucleus forms, establishes its peripheral projections, and the dimorphism in cell number emerges. A preliminary report of some of these observations has been published previously (Sengelaub and Arnold, 1984). 

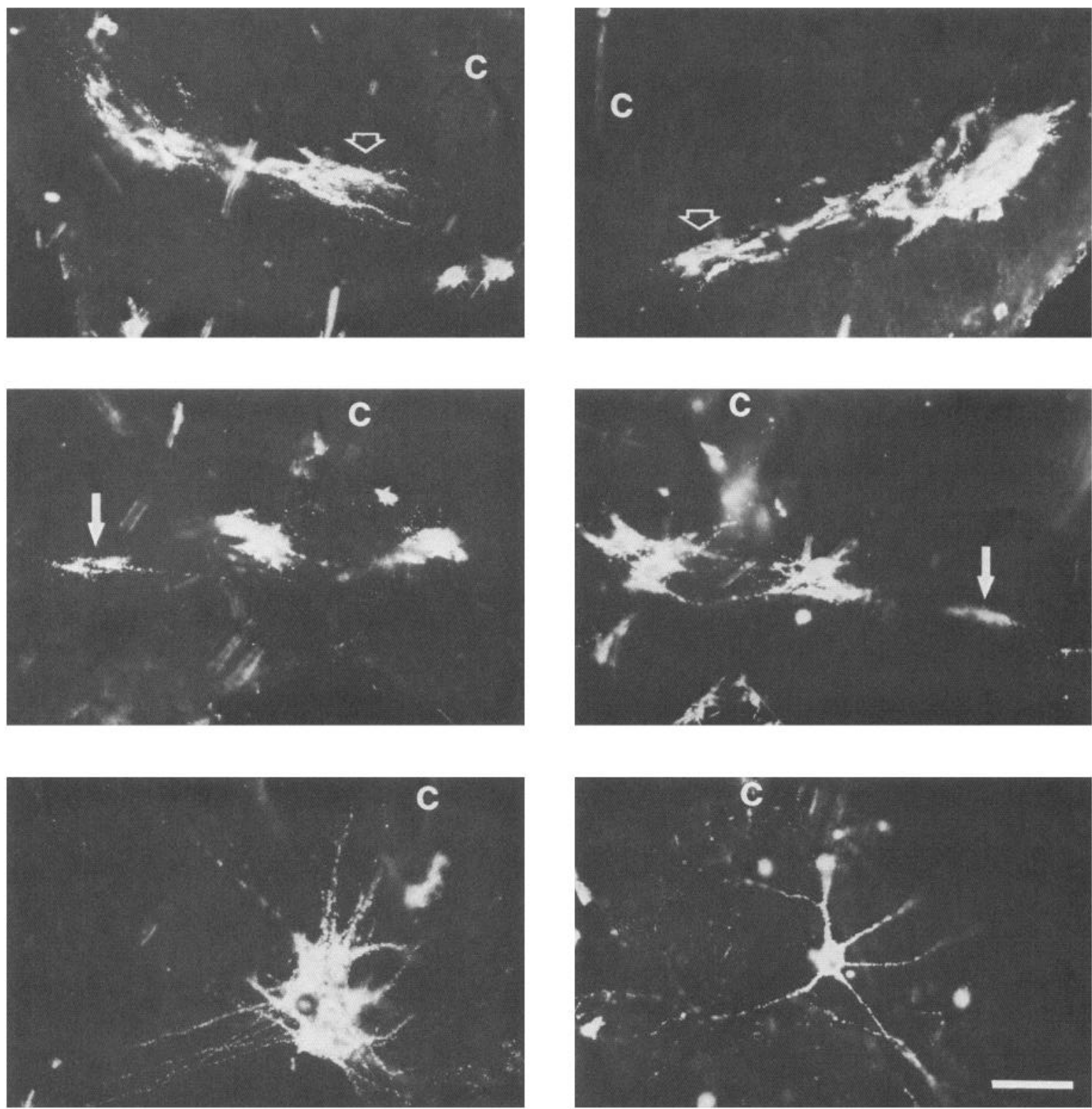

Figure 1. Dark-field photomicrographs of $40 \mu \mathrm{m}$ transverse sections through the lumbar spinal cord showing SNB motoneurons labeled after injections of cholera toxin-HRP into the bulbocavernosus muscle in males (left) and females (right). Although dark-field illumination may obscure individual cells due to labeling density, it is used here because of its superior sensitivity to fine fibers and lightly labeled cells, which would not be visible in bright-field photomicrographs. At E18 (top), labeled motoneurons can be seen in the medially located SNB (open arrows), laterally across the ventral horn, and in the lateral motor column in both sexes. At E22 (middle), the number of labeled motoneurons in the SNB has increased and ectopic labeled cells (solid arrows) can be seen lateral to the SNB in both sexes. At P10 (bottom), many labeled motoneurons can be seen in the male SNB, while only one is present in the female SNB shown. $C=$ central canal and midline. Calibration bar, $50 \mu \mathrm{m}$. See Figure 2 for pattern of labeling relative to adjacent cell groups.

Table 1. Number of animals per group by day of injection

\begin{tabular}{llllllll} 
& \multicolumn{9}{l}{ Age at injection } & & $\begin{array}{l}\text { Total } \\
\text { Group }\end{array}$ & E18 & E20 & E22 & P1 & P4 & P10 & no. \\
\hline Males & 6 & 5 & 6 & 12 & 7 & 7 & 43 \\
Females & 7 & 4 & 5 & 9 & 6 & 9 & 40 \\
TP-females & 5 & 5 & 4 & 5 & 3 & 6 & 28 \\
$\quad$ Total $(n)$ & & & & & & & 111 \\
\hline
\end{tabular}

\section{Materials and Methods}

\section{Animals}

Proestrous female rats (Sprague-Dawley, Simonsen Laboratories) were placed together with males overnight and sperm-positive females were identified the following morning. All fetal ages were calculated from the day sperm was observed, designated as embryonic day (E) 1 , and fetuses were obtained at E18, E20, and E22. Additionally, animals were obtained for P1, P4, and P10 (P1 = the day of birth), and only animals delivered at E23 were included. These ages were chosen because they encompass the period during which sex differences in SNB motoneuron number develop (Nordeen et al., 1984, 1985). In all cases, ages given refer to the age at time of HRP injection.

A total of 43 males and 40 females were used to determine the normal 



Figure 2. Camera lucida drawings of the same sections as shown in Figure 1 to show number of cells and pattern of labeling relative to adjacent cell groups. Boxes indicate areas of photomicrographs. $S N B$, spinal nucleus of the bulbocavernosus; $D L N$, dorsolateral nucleus; $R D L N$, retrodorsolateral nucleus; $V M P$, ventral motor pool (present only in P10 sections, which are more caudal relative to those at E18 and E22). Calibration bar, $500 \mu \mathrm{m}$.

development of SNB motoneuron projections and cell number. To study the effect of androgens on these features of SNB development, an additional set of 28 females treated with TP perinatally were also examined. Pregnant dams received daily subcutaneous injections of TP (2 $\mathrm{mg} / \mathrm{d})$ dissolved in sesame oil on E16-E22. Pups born to TP-treated dams were cross-fostered to other lactating females and injected with TP $(1 \mathrm{mg} / \mathrm{d})$ subcutaneously on P1, P3, and P5. This regimen of TP treatment produces masculinized females whose SNB motoneuron numbers are indistinguishable from those of normal males (Nordeen et al., 1984, 1985). Table 1 summarizes the ages and numbers of animals used.

\section{HRP labeling}

For fetal injections of HRP, pregnant rats were anesthetized with urethane, placed on a heating pad, and maintained at $37^{\circ} \mathrm{C}$. An incision was made across the abdomen and the uteri elevated and bathed with a modified Krebs solution. Fetuses were exteriorized by making an incision through the uterus and fetal membranes with care not to damage the umbilical cords, which remained intact throughout the procedure. After exposing the perineal musculature, $0.05 \mu \mathrm{l}$ of a $0.2 \%$ solution of cholcra toxin-HRP (List Biological) was pressure-injected into the bulbocavernosus muscle, identifiable at all ages examined by its characteristic appearance and position at the base of the phallus. Alternatively, HRP $(20 \% \mathrm{wt} / \mathrm{vol}$, Sigma type VI) was first dissolved in polyacrylamide gel $(10 \% \mathrm{wt} / \mathrm{vol})$ and allowed to polymerize. Small pieces of the HRPgel $\left(0.25 \mathrm{~mm}^{3}\right)$ were placed in the tip of a modified 30 gauge needle and deposited into the muscle by a fine wire attached to the plunger of the syringe (Bennet et al., 1983). After HRP injection, fetuses were allowed to survive from 4-6 hr, depending on the age of the fetus, which proved to be quite adequate for HRP labeling.

For postnatal HRP injections, animals were anesthetized by hypothermia and the perineal muscles exposed. HRP was delivered as described above, and animals were allowed to survive for $16-24 \mathrm{hr}$, again depending on the age of the animal.

\section{Histochemistry}

After the appropriate survival time, all animals were perfused with saline followed by cold $1 \%$ paraformaldehyde $/ 1.25 \%$ glutaraldehyde fixative in $0.1 \mathrm{M}$ phosphate buffer, $\mathrm{pH}$ 7.2-7.4. Spinal cords were removed and postfixed in cold fixative for $5 \mathrm{hr}$ and then placed in cold phosphate buffer overnight. The relevant segment of the spinal cord was then embedded in gelatin and the block further hardened by immersion in cold $2 \%$ glutaradehyde $/ 10 \%$ sucrose in phosphate buffer. Frozen sections were taken transversely through the spinal cords at 20 and $40 \mu \mathrm{m}$, collected in phosphate buffer and reacted immediately with tetramethyl benzidine (TMB) by the method of Mesulam (1978). After processing, the sections were mounted on gelatin-subbed slides and counterstained with either thionin or neutral red. Alternate sections were examined under both bright- and dark-field illumination, and plots of the positions of labeled motoneurons were made with the aid of a camera lucida. Counts of labeled motoneurons in the SNB nucleus were made under bright-field illumination, where somas, processes, and nuclei could be visualized, and cytoplasmic inclusion of HRP reaction product confirmed. These counts were corrected for frequency of encounter by cell size and section thickness by the method of Abercrombie (Konigsmark, 1970) and by the proportion of the cord examined in order to generate 


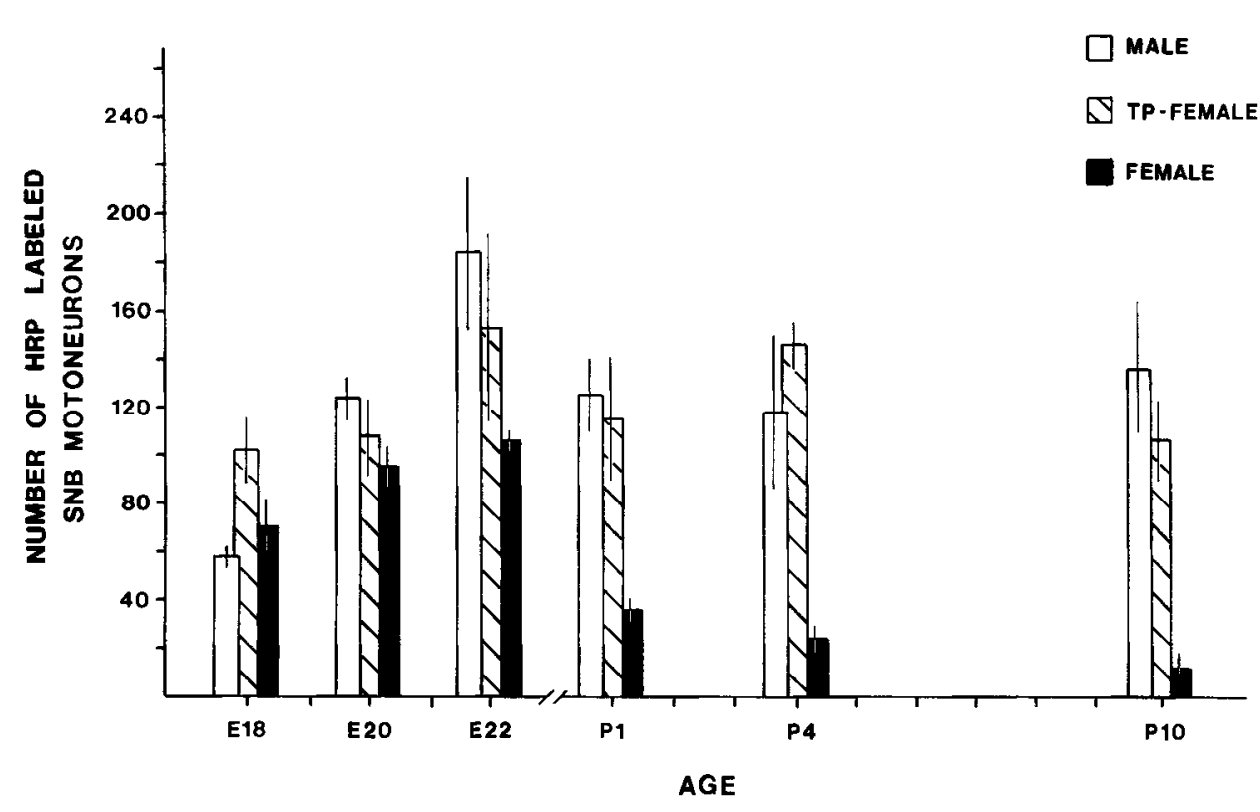

Figure 3. Number of SNB motoneurons labeled after injections of HRP into the bulbocavernosus muscle from E18 through P10 for males (open bars), females (solid bars), and TP-females (hatched bars). Counts exclude ectopic labeled cells. Bar height represents the mean $\pm \mathrm{SEM}$, $n=3-12$ per point. motoneuron number estimates that could be compared to total counts of SNB motoneurons from Nissl-stained material. Only those cords with HRP-labcled SNB motoncurons wcre included in this study (Table 1).

To confirm HRP injection sites and identify potential spurious labeling by HRP spread to other muscles, the perineal musculature was also processed and examined as described above.

\section{Results}

HRP injections into the bulbocavernosus muscle labeled motoneurons in the SNB of all groups at all ages examined (Figs. $1,2)$. Although the numbers of labeled motoneurons did not differ by the method of HRP delivery, motoneurons labeled with cholera toxin-HRP were consistently more intensely labeled, typically displaying well-labeled dendrites and axons at all ages. Leakage of HRP to neighboring muscles also did not differ by method of HRP delivery and, in any case, was minimal, typically spreading into the ischiocavernosus muscle, which is dorsal and rostral to the bulbocavernosus. The ischiocavernosus is innervated by motoneurons in the dorsolateral nucleus (Breedlove and Arnold, 1980; Schroder, 1980), and labeled motoneurons were observed in the dorsolateral nucleus in substantial numbers only after HRP injections at E18. At all other ages, labeling was typically restricted to motoneurons in or near the SNB (see below).

Counts of HRP-labeled motoneurons in the SNB differed over time and across groups, and we have presented these data in two forms. In order to compare groups directly, the number of SNB motoneurons labeled after injections of HRP into the bulbocavernosus over days is plotted in Figure 3. To demonstrate how the number of HRP-labeled SNB motoneurons changes in relation to the overall SNB motoneuron population, we have plotted these data against counts of total SNB motoneurons made from Nissl-stained material (from Nordeen et al., 1985) in Figure 4.

At E1 8, the number of HRP-labeled motoneurons in the SNB of males and females was not different $[F(1,93)=0.23, p>0.6$ (male $\bar{x}=58.2 \pm 3.9 \mathrm{SEM}$; female $\bar{x}=70.6 \pm 12.5 \mathrm{SEM}$ )] indicating that there are substantial early projections of SNB motoneurons to their target muscles in both sexes. Importantly, these projections are present well before the onset of the differential cell degeneration and development of sex differences in motoneuron number, which are discernible by E22 (Figs. 1-4). Interestingly, the number of labeled motoneurons in the SNB of TP-treated females was larger than that of normal males or females $(\bar{x}=101.9 \pm 14.2 \mathrm{SEM})$, although this difference was not statistically significant $[F S(1,93)<2.43, p>0.1]$. Compared to normal males and females, TP-females also displayed a greater labeling of neural processes (Fig. 5). Although it appears in Figure 4 that all or, in some cases, more than the total number of motoneurons in the SNB can be labeled with HRP at E18, it should be noted that counts of HRP-labeled motoneurons were obtained from animals that were slightly older (because of the requirement of transport time) than animals used for determining the overall number of motoneurons in the SNB. Because SNB motoneuron number is increasing rapidly during this period (see below), later sacrifice times would result in greater numbers of motoneurons being present in the SNB.

Although there is no difference between males and females at E18, the number of HRP-labeled motoneurons is small compared to later values, and by E22 the number of HRP-labeled SNB motoneurons has increased in all groups. By E22, an average of $184.4( \pm 31.0$ SEM) HRP-labeled motoneurons are present in the SNB of males, compared to 153.1 ( \pm 39.7 SEM) and $105.8( \pm 9.5$ SEM) in TP-females and normal females, respectively (Fig. 3). Numbers of HRP-labeled SNB motoneurons in males do not differ from TP-females at any time $[F(1,93)=$ $0.18, p>0.6]$, but males differ significantly from females as early as $\mathrm{E} 22[F(1,93)=7.16, p<0.01]$, while TP-females do not differ from normal females until P1 $[F(1,93)=9.37, p<$ $0.01]$.

During the increase in SNB motoneuron number from E18 to E22, HRP-labeled cells can be seen outside the confines of the presumptive SNB nucleus (Fig. 6). Although labeled with HRP, these ectopic cells were not included in counts of SNB motoneurons. These cells are typically elongated, possess what appear to be lcading and trailing processes, and are located between the medially positioned SNB and the lateral motoneuron columns. The frequency of these ectopic cells does not differ across groups and decreases over this period with few or none labeled by the day of birth. While the presence of labeled cells in the lateral motor columns at E18 is most likcly the result of HRP spread at the injection site, labeled cells located midway between the two motor columns at E20 and E22 can still be seen after injections that were apparently confined to the bulbocavernosus. The characteristic location of these ectopic labeled cells further decreases the probability of their being the result of HRP spread to inappropriate muscles, as the only 

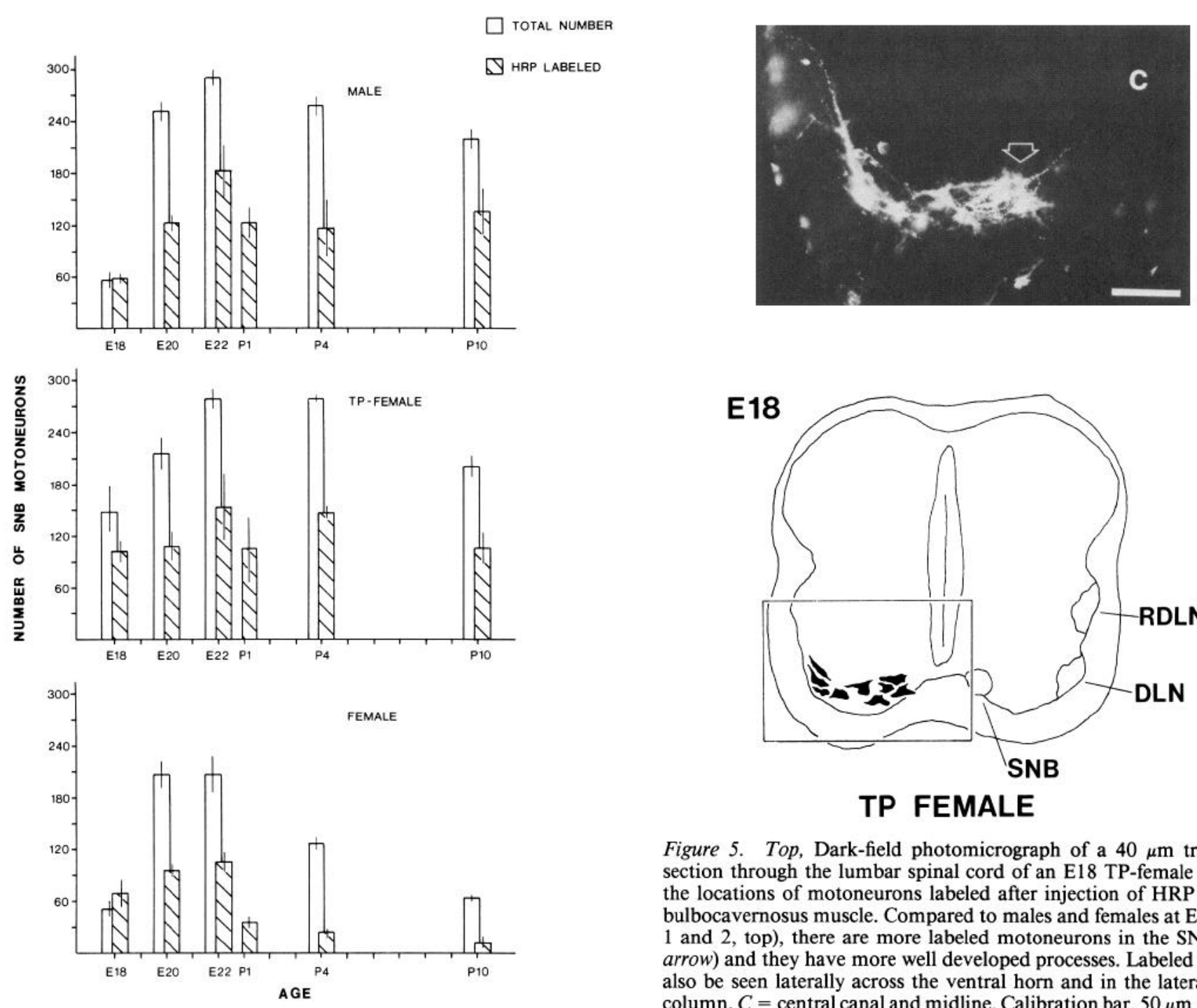

Figure 4. Number of SNB motoneurons labeled after injections of HRP into the bulbocavernosus muscle (hatched bars) from E18 through P10 relative to overall counts of SNB motoneurons (open bars) for males (top), TP-females (middle), and females (bottom). Bar height represents the mean \pm SEM, $n=3-12$ per point.

motoneurons in older animals with a somewhat similar position are located more ventrally and in more caudal levels of the cord-the ventral motor pool (Schroder, 1980).

Between E22 and the day of birth (P1) there is an abrupt decline in the number of HRP-labeled SNB motoneurons in all groups (Fig. 3), which is particularly large for females $(66 \%$ decline vs $32 \%$ for males and $25 \%$ for TP-females). This abrupt decline in labeled motoneuron number is significant for males and females $[F s(1,93)>5.86, p<0.05]$, although not for TPfemales $[F(1,93)=1.53, p>0.05]$. From $\mathrm{P} 1$ to $\mathrm{P} 10$, the number of HRP-labeled SNB motoneurons remains relatively constant for males $(\bar{x}=114.9 \pm 12.9$ SEM $)$; this contrasts with overall counts (Fig. 4; counts that include motoneurons with projections to muscles other than the bulbocavernosus) which show a significant decline of approximately $25 \%$ from E22 to P10. As in males, counts of HRP-labeled SNB motoneurons in TP-females at P1 do not differ from those at P10, although their overall cell numbers have declined by $\mathrm{P} 10$ as well. However, counts of HRP-labeled motoneurons in females decline an additional $23 \%$ from $\mathrm{P} 1$ to $\mathrm{P} 10$, resulting in an overall decline of $89 \%$ from E22 to P10, in contrast to only a $70 \%$ decline in females is highly significant $[F(1,93)=13.71, p<0.001]$. Thus, by the day of birth both males and TP-females appear to have stabilized their projections to the bulbocavernosus, whereas females continue to lose these motoneurons.

By P10, counts of HRP-labeled SNB motoneurons for males and TP-females do not differ $[F(1,93)=1.47, p>0.2]$, but both have significantly more labeled motoneurons than females $[F s(1,93)>15.29, p<0.001)$. This difference is identical to that seen in overall counts of SNB motoneurons, which are in their adult ranges by this time.

\section{Discussion}

Counts of HRP-labeled motoneurons in the SNB after injections into the developing bulbocavernosus muscle confirm in detail the patterns of change and relative magnitudes of SNB motoneuron numbers previously reported for overall counts in normal males and females, as well as TP-treated females (Nordeen et al., 1984, 1985). Additionally, injections of HRP demonstrate that in both sexes SNB axons have contacted their target musculature before the onset of the differential cell degeneration and development of sex differences in motoneuron number. 

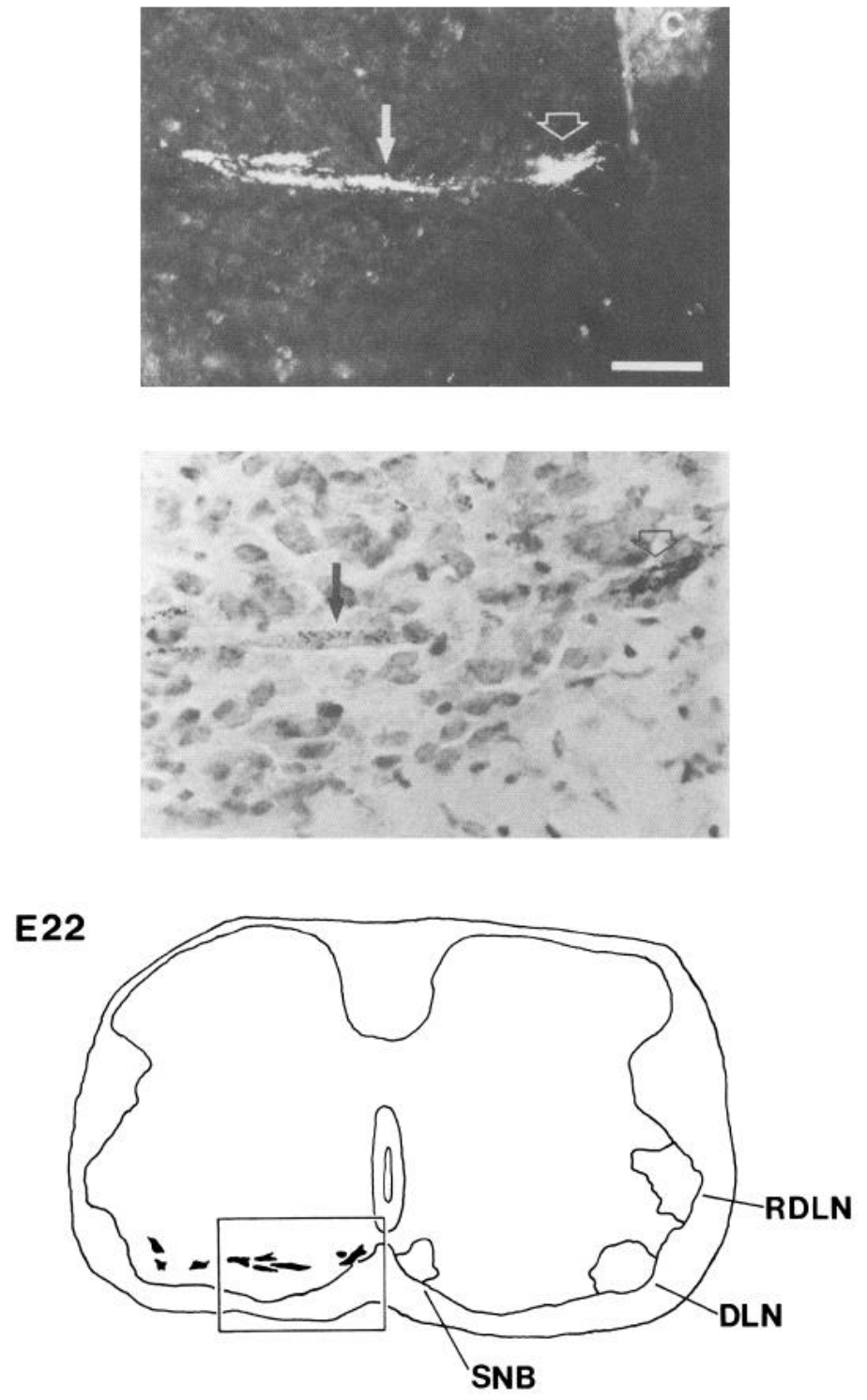

MALE

Figure 6. Dark-field (top) and bright-field (middle) photomicrographs of a $40 \mu \mathrm{m}$ transverse section through the lumbar spinal cord of an E22 male after injection of HRP into the bulbocavernosus muscle. Labeled are SNB motoneurons (open arrow), as well as several elongated ectopic cells lateral to the SNB. Solid arrow indicates the same HRP-labeled ectopic cell in each photomicrograph. $C=$ central canal and midline. Calibration bar, $50 \mu \mathrm{m}$. Bottom, Camera lucida drawing of the same section to show the number of cells and the pattern of labeling relative to adjacent cell groups. Box indicates area of dark-field photomicrograph; abbreviations as in Figure 2.

\section{Initial axon outgrowth and formation of the $S N B$}

At E18, both males and females have approximately 60-70 labeled motoneurons in the SNB (Figs. 1-4), demonstrating that both sexes have sent axons into the periphery by E18. This number is small relative to later values and indicates that the small number of motoneurons observable in Nissl-stained material at this age is not due to insufficient differentiation such that motoneurons might not be recognized. This idea is further supported by the finding that the motoneurons of the lateral motor columns, which have mitotic histories identical to SNB motoneurons (Breedlove et al., 1983), are readily identifiable by morphological criteria at this age. Although the HRP counts are equal to or in some cases greater than overall counts of SNB motoneurons (Fig. 3), given the rapid increase in SNB motoneuron number during the late prenatal period, it is not surprising that later sacrifice times (i.e., slightly older ages) produce animals with greater than expected numbers of HRP-labeled motoneurons in the SNB. Interestingly, TP-females have more motoneurons in their SNB in both overall and HRP counts than either normal males or females, and these motoneurons appear to be more differentiated in that they possess more complex dendritic arbors (Fig. 5). Given that androgens can promote neurite outgrowth (Toran-Allerand, 1976), treatment with TP may accelerate the development of the SNB and its motoneurons beyond that typical of males at E18. Sex differences in plasma androgen levels are first evident at E18 (Weisz and Ward, 1980 ), so it is possible that our beginning TP injections into females at E16 may initiate the masculinization process earlier than it would normally occur in males.

\section{Increases in motoneuron number and the presence of ectopic cells}

All groups show an increase in the number of motoneurons in the SNB from E18 to E22. While it is possible that the increase in the number of HRP-labeled cells is the result of continued axon outgrowth into the target musculature, this is difficult to reconcile with the obvious lack of motoneurons in the SNB at E18 and the subsequent increases seen in overall counts. A similar increase in counts of HRP-labeled motoneurons in the mouse lateral motor column was observed early in development by Lance-Jones (1982); she interpreted this as a result of continued migration. During the increase in SNB motoneuron number, labeled cells can be seen outside the SNB, midway between it and the lateral motoneuron columns (Fig. 6). These cells were located in areas where motoneurons are not found in more mature animals and were not seen after the period of increase in SNB motoneuron number. Additionally, these cells were labeled after injections into the bulbocavernosus muscle and were present at E20 and E22 in animals in which the only other cells labeled were SNB motoneurons. As can be seen in Figure 6, these ectopic cells were typically elongate in shape and had simple processes extending outward along the long axis of the cell, which resembled leading and trailing processes. Because of their coincidence in time with the increase in SNB motoneuron number and the suggestive morphology of these cells, we have hypothesized that these ectopic labeled cells are in the process of migrating medially into the SNB, perhaps as a secondary migration similar to that seen in the cells of the column of Terni in the chick spinal cord (Hamburger and Levi-Montalcini, 1950). At E18 (the earliest age studied) a small fraction of the eventual SNB population is present in its medial location; thus, it is possible that not all SNB motoneurons migrate from the lateral motoneuron columns, although the vast majority appear to.

Retrograde labeling of motoneurons that have yet to complete their migration has been observed in other developing systems (Farel and Bemelmans, 1980; Heaton et al., 1978; but see also Smith and Hollyday, 1983). While it is unlikely that these ectopic labeled cells are not motoneurons, it is possible that these labeled cells withdraw their axons from the bulbocavernosus or degenerate during the period of increase in SNB motoneuron number. Such a retraction or death would explain the absence of these ectopic cells after the day of birth but would still leave the increase in SNB motoneuron number unaccounted for. Therefore, at present we favor the hypothesis that the prenatal increase in SNB motoneuron number results from a migration of motoneurons into the SNB from the lateral motor column.

The increase in SNB motoneuron number from E18 to E22 is substantially greater in males and TP-females than in normal females (Fig. 3). Because this increase is sexually dimorphic and 
influenced by androgens, it is possible that the lateral-to-medial migration of motoneurons into the SNB may itself be subject to regulation by androgens. While the greater number of labeled motoneurons in TP-females would be consistent with this, by E22 TP-females have no more SNB motoneurons than males. Furthermore, by E22 cell death in the SNB has begun, as indicated by the observation of numerous degenerating cells in and around the nucleus, and the greater numbers of SNB motoneurons in males and TP-females compared to females could be the result of androgen prevention of cell death prenatally, as opposed to an androgenic stimulation of migration (Nordeen et al., 1984, 1985).

\section{Development of dimorphism in motoneuron number and projections}

After E22, overall motoneuron number in the SNB declines by about $25 \%$ in males and TP-females while declining $70 \%$ in normal females; by P10, motoneuron numbers are in their adult range. Although overall cell counts in all groups continue to decline from E22 to P10, after an initial decline (E22 to P1) counts of the number of HRP-labeled cells after injections into the bulbocavernosus in males and TP-females show no significant changes, suggesting that the changes seen in overall counts reflect the loss of SNB motoneurons that innervate muscles other than the bulbocavernosus. Counts of HRP-labeled cells in females also show an initial decline from E22 to P1; but in contrast to males and TP-females, labeled cell numbers in the SNB continue to decline significantly after $P 1$, until few or no SNB motoneurons are labeled at P10. From E22 to P10, counts of HRP-labeled SNB motoneurons decline by $89 \%$, whereas overall motoneuron counts decline by only $70 \%$. This difference suggests that the precipitous decline in SNB motoneuron number in females is probably due to losses of motoneurons with projections to all of the SNB target muscles, but especially those motoneurons projecting to the bulbocavernosus and levator ani, which by P10 have regressed substantially. Thus, by P10 and the end of the cell death period in the SNB, the adult differences in SNB motoneuron number and projection pattern have essentially been established.

\section{Early projections, androgens, and \\ regulation of cell survival}

These results demonstrate that both males and females send axons into the periphery by E18 in equivalent numbers, and these axons are therefore present before the onset of the differential cell death and the development of sex differences in SNB motoneuron number. Because the magnitude of axon outgrowth at E18 is apparently not different in males and females, it is unlikely that androgens are critical in this process. However, it is still possible that other aspects of target innervation, stabilization of synaptic contacts, or some other factors critical for motoneuron survival are under androgenic regulation. Both the motoneurons of the SNB and its target muscles (with the possible exception of the anal sphincter) accumulate androgens (Breedluve and Arnold, 1980, 1983c; Dube et al., 1976), and therefore at least two potential sites for androgen action are available. For example, it is possible that androgens could regulate SNB motoneuron survival by acting directly on the SNB motoneurons themselves. Alternatively, the fact that SNB motoneurons of both sexes have their axons at their target musculature well before the onset of cell death suggests that androgens could act at the target musculature and therefore influence motoneuron survival and the development of sex differences through the interaction of the motoneurons with their target muscles.

Finally, female SNB motoneurons can be labeled with HRP at E18-E22 in numbers substantially greater than those labeled after the period of cell death. Thus, as in other neuromuscular systems, motoneurons that will subsequently degenerate appar- ently develop their appropriate projections (Chu-Wang and Oppenheim, 1978). It should therefore be clcar that the greatcr loss of SNB motoneurons in normal females is not the result of a failure of these motoneurons to send axons to the periphery.

\section{References}

Bennet, M. R., P. A. McGrath, D. F. Davey, and I. Hutchinson (1983) Death of motoneurons during the postnatal loss of polyneuronal innervation of rat muscles. J. Comp. Neurol. 218: 351-363.

Breedlove, S. M. (1984) Androgen forms sexually dimorphic spinal nucleus by saving motoneurons from programmed death. Soc. Neurosci. Abstr. 10: 927

Breedlove, S. M., and A. P. Arnold (1980) Hormone accumulation in a sexually dimorphic motor nucleus in the rat spinal cord. Science 210: 564-566.

Breedlove, S. M., and A. P. Arnold (1983a) Hormonal control of a developing neuromuscular system. I. Complete demasculinization of the male rat spinal nucleus of the bulbocavernosus using the antiandrogen flutamide. J. Neurosci. 3: 417-423.

Breedlove, S. M., and A. P. Arnold (1983b) Hormonal control of a developing neuromuscular system. II. Sensitive periods for the androgen-induced masculinization of the rat spinal nucleus of the bulbocavernosus. J. Neurosci. 3: 424-432.

Breedlove, S. M., and A. P. Arnold (1983c) Sex differences in the pattern of steroid accumulation by motoneurons of the rat lumbar spinal cord. J. Comp. Neurol. 215: 211-216.

Breedlove, S. M., C. L. Jordan, and A. P. Arnold (1983) Neurogenesis of motoneurons in the sexually dimorphic spinal nucleus of the bulbocavernosus in rats. Dev. Brain Res. 9: 39-43.

Chu-Wang, I. G., and R. W. Oppenheim (1978) Cell death of motoneurons in the chick embryo spinal cord. II. A qualitative and quantitative analysis of degeneration in the ventral root including evidence for axon outgrowth and limb innervation prior to cell death. J. Comp. Neurol, 177: 59-86.

Cihak, R., E. Gutmann, and V. Hanzlikova (1970) Involution and hormone-induced persistence of the muscle sphincter (levator) ani in female rats. J. Anat. 106: 93-110.

Dube, J. Y., R. Lesage, and R. R. Tremblay (1976) Androgen and estrogen binding in rat skeletal and perineal muscles. Can. J. Biochem. 54: $50-55$.

Farel, P. B., and S. E. Bemelmans (1980) Retrograde labeling of migrating spinal motoneurons in bullfrog larvae. Neurosci. Lett. 18 . 133-136.

Hamburger, V. (1975) Cell death in the development of the lateral motor column of the chick embryo. J. Comp. Neurol. 160: 535-546.

Hamburger, V., and R. Levi-Montalcini (1949) Proliferation, differentiation, and degeneration in the spinal ganglia of the chick embryo under normal and experimental conditions. J. Exp. Zool. 162: 457502 .

Hamburger, V., and R. Levi-Montalcini (1950) Some aspects of neurocmbryology. In Genetic Neurology, P. Weiss, ed., pp. 128-165, University of Chicago Press, Chicago.

Heaton, M. B., S. A. Moody, and M. E. Kosier (1978) Peripheral innervation by migrating neuroblasts in the chick embryo. Neurosci. Lett. 10: 55-59.

Konigsmark, B. W. (1970) Methods for the counting of neurons. In Contemporary Research Methods in Neuroanatomy, W. J. H. Nauta and S. O. E. Ebbeson, eds., pp. 315-340, Springer-Verlag, New York.

Lance-Jones, C. L. (1979) The morphogenesis of the thigh of the mouse with special reference to tetrapod muscle homologies. J. Morphol. 162: 275-310.

Lance-Jones, C. L. (1982) Motoneuron cell death in the developing lumbar spinal cord of the mouse. Dev. Brain Res. 4: 473-479.

Landmesser, L. (1980) The generation of neuromuscular specificity. Annu. Rev. Neurosci. 3: 279-302.

McKenna, K. E., and I. Nadelhaft (1984) Organization of the pudendal nerve in the male and female rat. Soc. Neurosci. Abstr. 10:902.

Mesulam, M. M. (1978) Tetramethyl benzidine for horseradish peroxidase neurohistochemistry: A noncarcinogenic blue reaction-product with superior sensitivity for visualizing neural afferents and efferents. J. Histochem. Cytochem. 27: 106-117.

Nordeen, E. J., K. W. Nordeen, D. R. Sengelaub, and A. P. Amold (1984) Ontogeny of sexual dimorphism in a rat spinal nucleus: $I$. Hormonal control of neuron number. Soc. Neurosci. Abstr. 10:454. 
Nordeen, E. J., K. W. Nordeen, D. R. Sengelaub, and A. P. Arnold (1985) Androgens prevent normally-occurring cell death in a sexually dimorphic spinal nucleus. Science 229: 671-673.

Oppenheim, R. W. (1981) Neuronal death and some related regressive phenomena during neurogenesis: $A$ selected historical review and progress report. In Studies in Developmental Neurobiology, W. M. Cowan, ed., pp. 74-133, Oxford U.P., New York.

Romer, A. S. (1927) The development of the thigh musculature of the chick. J. Morphol. 43: 347-385.

Schroder, H. D. (1980) Organization of the motoneurons innervating the pelvic muscles of the rat. J. Comp. Neurol. 192: 567-587.

Sengelaub, D. R., and A. P. Arnold (1984) Ontogeny of sexual dimorphism in a rat spinal nucleus: II. Formation and loss of early projections. Soc. Neurosci. Abstr. 10: 453.
Smith, C. L., and M. Hollyday (1983) The development and postnatal organization of motor nuclei in the rat thoracic spinal cord. J. Comp. Neurol. 220: 16-28.

Toran-Allerand, C. D. (1976) Sex steroids and development of the newborn mouse hypothalamus and preoptic area in vitro: Implications for sexual differentiation. Brain Res. 106: 407-412.

Tosney, K. W., and L. T. Landmesser (1984) Pattern and specificity of axonal outgrowth following varying degrees of chick limb bud ablation. J. Neurosci. 4: 2518-2527.

Weisz, J., and I. L. Ward (1980) Plasma testosterone and progesterone titers of pregnant rats, their male and female fetuses, and neonatal offspring. Endocrinology 106: 306-316. 